\title{
SISTEMA DE AVALIAÇÃO DA EDUCAÇÃO DE NITERÓI: A PERCEPÇÃO DE PROFESSORES NO CONTEXTO DA PRÁTICA
}

Carla Cristina Martins da Conceição Vasconcellos

Lúcia Velloso Maurício $^{(*)}$

Nas últimas décadas, o debate acerca da avaliação tem sido constante. No Brasil, diversas esferas da sociedade têm reivindicado a divulgação de informações relacionadas à qualidade do ensino nas instituições educacionais brasileiras. Nos anos 1990, configura-se uma política de avaliação que

engloba diferentes programas, tais como o Sistema Nacional de Avaliação da Educação Básica - SAEB, [...] a Prova Brasil e o Índice de Desenvolvimento da Educação Básica - IDEB. Em conjunto, estes sistemas, ao lado da Avaliação da PósGraduação da Capes - o mais antigo sistema de avaliação do país no setor da educação -, configuram um macrossistema de avaliação da qualidade da educação brasileira (CASTRO, 2009, p.5).

A política de avaliação vigente tem como um dos efeitos o surgimento de sistemas de avaliação estaduais e municipais, na tentativa de busca pela qualidade da educação apresentada pelos resultados das avaliações nacionais.

A política de avaliação externa fomentada pelo governo federal coloca em evidência a complexidade da educação brasileira e como vem sendo conduzida, ao longo dos anos, suscitando muitas tensões no cotidiano escolar, principalmente para professores e gestores, colocando em voga a eficácia escolar e a qualidade da educação. Tais tensões têm relação direta com a política de responsabilização, em que os resultados de avaliações são utilizados por muitas secretarias de educação para punir, premiar e responsabilizar escolas e professores pelos resultados obtidos pelos alunos. Segundo Esteban e Afonso (2010, p. 9) “o campo da avaliação, desde a sua constituição, está em permanente mutação, embora nas últimas décadas venha sendo particularmente desafiado, nos âmbitos teórico-metodológicos e práticos, por acontecimentos e mudanças globais, nacionais e locais." Esse contexto se apresenta na conjuntura educacional brasileira a partir da criação do Sistema de Avaliação da Educação Básica (SAEB), que tem seu início em 1988, e a primeira edição

\footnotetext{
${ }^{(*)}$ Carla Cristina Martins da Conceição Vasconcellos. Da Secretaria de Estado da Educação (SEEDUC/RJ), e da . Fundação Municipal de Educação de Niterói.

Lúcia Velloso Maurício. Da Faculdade de Formação de Professores (FFP).da Universidade do Estado do Rio de Janeiro (UERJ).
} 
em 1990. Segundo o Instituto Nacional de Estudos e Pesquisas Educacionais Anísio Teixeira (INEP), o SAEB tem objetivo de dar clareza à sociedade sobre a qualidade da educação brasileira em várias instâncias, além de subsidiar as tomadas de decisões no que diz respeito à melhoria da educação no Brasil. Para Pestana (1998, p. 66), "um sistema nacional de avaliação poderia trazer informações úteis sobre: o que estava sendo gerado no setor educacional, como, onde, quando e quem era responsável pelo produto obtido".

Nesse estudo abordamos a criação e implantação do Sistema de Avaliação da Educação de Niterói (SAEN), instituído em 2013, na educação pública municipal. Tal sistema de avaliação está estruturado em quatro dimensões: Gestão da Rede Municipal; Gestão Escolar; Gestão do Trabalho Pedagógico e Gestão das Aprendizagens.

Essa pesquisa nasceu de observações cotidianas, abordadas adiante, da realidade latente encontrada na Rede Estadual do Rio de Janeiro e na Rede Municipal de Niterói, da qual fomos professoras docentes. Integramos o corpo técnico da Coordenação de $3^{\circ}$ e $4^{\circ}$ ciclos, acompanhando escolas e professores dos anos finais do ensino fundamental e participamos da assessoria responsável pela implementação do Sistema de Avaliação da Educação de Niterói (SAEN). Nossa experiência como professoras permitiu observar a complexidade da matriz curricular deste segmento, que na rede municipal é composta por nove áreas do conhecimento, em que lecionam nove diferentes professores. Além disso, os indicadores educacionais nos anos finais são menos favoráveis, se comparados com os dos anos iniciais do ensino fundamental.

A relevância da temática se deve à centralidade que a avaliação externa vem ocupando nas discussões educacionais no Brasil nos últimos trinta anos nas esferas nacional, estadual e municipal. A quantidade de estados e de municípios que criaram sistemas próprios de avaliação demonstra como essa política vem sendo incorporada às diferentes realidades da educação brasileira. Até 2014, dezenove estados brasileiros possuíam sistemas de avaliação próprios (MACHADO; ALAVARSE; ARCAS, 2015). Em recente estudo, Bauer et al. (2015) constatam que a expansão das avaliações próprias na gestão municipal ocorre a partir de 2005; até 2004, havia 103 municípios com ações próprias de avaliação e entre 2005 e 2013 surgiram mais 1.280 novas iniciativas. A discussão ganha ainda mais expressão, a partir de 2005, com a instituição da Prova Brasil, avaliação censitária, bianual, que avalia os alunos do $5^{\circ}$ e $9^{\circ}$ anos de escolaridade do ensino fundamental. E, principalmente, a partir de 2007, com a criação do Índice de Desenvolvimento da Educação Básica (IDEB) que "surge com o objetivo de ancorar um sistema de metas educacionais" (FERNANDES, 2016, p. 103). Esse indicador passou a ser apresentado como sinônimo de qualidade do ensino, provocando inquietações no sistema educacional brasileiro. Silva (2009) destaca que qualidade é 
um termo de caráter polissêmico e que um sistema de avaliação de abrangência nacional terá dificuldade para retratar as particularidades inerentes a cada escola. "A qualidade social da educação escolar não se ajusta, portanto, aos limites, tabelas, estatísticas e fórmulas numéricas que possam medir um resultado de processos tão complexos e subjetivos" (p. 225).

$\mathrm{Na}$ educação brasileira o termo qualidade da educação vem sofrendo deslocamentos ao longo da história da educação, e com mais intensidade a partir da criação do IDEB em 2007. Esse índice retrata o desempenho da educação através da combinação de indicadores de fluxo e dos resultados do SAEB e da Prova Brasil, obtidos por estudantes ao final de cada etapa do sistema de ensino (FERNANDES, 2007). Esse indicador tem recebido muitas críticas, em particular por difundir uma visão limitada da qualidade da educação, restrita apenas a avaliação dos alunos e ao fluxo escolar. A mídia utiliza o indicador para promover um ranking das escolas e sistemas de ensino, desviando o foco dos principais objetivos das avaliações externas e do IDEB - formulação de políticas públicas com base neste diagnóstico para contribuir com a melhoria do processo pedagógico. Sobre o uso equivocado feito pela mídia em torno dos resultados da Prova Brasil, Freitas (2013) argumenta que essa divulgação fomenta a comparação, a competição, a premiação e a punição.

Entendendo que a política de avaliação depende de sua incorporação pelo professor para produzir resultados significativos, esse estudo tem como objetivo analisar a visão dos professores dos anos finais do ensino fundamental sobre as políticas de avaliação educacional, sobretudo, após a constituição do SAEN em 2013, na rede municipal de educação de Niterói.

Antecederam ao SAEN, nos últimos vinte anos, na rede municipal de Niterói diferentes propostas pedagógicas relacionadas ao currículo e à avaliação: Avaliação Continuada: a experiência da FME/Niterói, de 1995; "Construindo a Escola do Nosso Tempo (primeira proposta de ciclos), instituída no ano de 1989; "Escola de Cidadania" (segunda proposta de ciclos) de 2008 e o "Referencial Curricular da Rede Municipal de Ensino de Niterói: uma construção coletiva, atual proposta, publicada em de 2010. Destaquem-se pesquisas anteriores que abordaram as políticas de avaliação e currículo da rede municipal de ensino de Niterói da última década do século XX e da primeira década do atual (FERNANDES, 2003; MATHEUS, 2009; AROSA e CUNHA, 2013).

Objetivamos, mais especificamente por meio das entrevistas, analisar como os professores do segundo segmento do ensino fundamental percebem os impactos do SAEN no cotidiano escolar. A análise dos documentos e das entrevistas foram realizadas tendo como embasamento teórico a abordagem do Ciclo de Políticas, sugerido por Ball e colaboradores (BOWE; BALL; GOLD, 1992) e explorada por Mainardes (2006). Esse referencial permite reinscrever a análise da política nas 
influências mútuas entre os contextos macro e micro. Além disso, enfatiza os processos micropolíticos e a ação dos profissionais que lidam com as políticas no nível local, lançando luz sobre as possibilidades de intervenção e mudança postas pelas interações entre o contexto global e o contexto local.

O Ciclo de Políticas é composto pelo Contexto de Influência, da Produção de Texto, da Prática, Contexto de Resultados e Efeitos e Contexto de Estratégia Política. Nessa análise, optamos por trabalhar com a articulação entre os três primeiros contextos. Esse referencial teórico possibilitou a análise dos documentos inerentes ao SAEN, como a Lei Municipal no 3.067/2013, que institui o sistema e a Portaria conjunta $\mathrm{n}^{\circ}$ 005/2015, editada pela Secretaria Municipal de Ciência e Tecnologia/Fundação Municipal de Educação de Niterói (SEMECT/FME), bem como as entrevistas realizadas com quatorze professores que atuam nas diferentes áreas do conhecimento nos anos finais do ensino fundamental da rede municipal em questão. Utilizamos a observação das práticas escolares, a princípio, para a formulação do problema da pesquisa e delimitação do seu objeto. Segundo Alves-Mazzotti e Gewandsznajder (1998, p. 164) "A observação de fatos, comportamentos e cenários é extremamente valorizada pelas pesquisas qualitativas”. Entretanto configurou-se como recurso bastante significativo para confrontar com as informações oriundas das entrevistas e dos documentos.

Segundo Ball em entrevista concedida a Avelar (2016, p. 6), ele e Bowe tentaram criar uma ideia de trajetória da política, ou seja, "pensar na política não como documento, ou uma coisa, mas sim uma entidade social que se move no espaço e o modifica enquanto se move, e modifica coisas nesse movimento, modifica o espaço pelo qual se move". O autor argumenta que considerando os contextos da influência, o contexto da produção do texto e o contexto da prática, a política pode ser "coisas diferentes nestes diferentes contextos" (p. 6).

O contexto de influência envolve a construção das políticas públicas, espaço em que há a disputa pelos sentidos a se legitimarem. Nesse contexto, atuam os partidos políticos, governos e os agentes dos processos. Ao analisar uma política pública sob esse paradigma, é possível identificar, dentre outros aspectos, as influências globais e locais, como no caso do SAEN, cuja criação está relacionada à política nacional de avaliação externa e aos resultados educacionais locais, nesse caso, a rede municipal de educação de Niterói.

Marcos da política de avaliação externa brasileira como o artigo 9 da LDBEN 9.394/96; a Lei 13.005/2014 (Plano Nacional de Educação) e o artigo 46 da Resolução CNE/CBE 4/2010, que define as Diretrizes Curriculares Nacionais Gerais para a Educação Básica, demonstram como a conjuntura nacional da política de avaliação influenciou o contexto local. Tal influência é perceptível no documento que regulamenta o SAEN - a Portaria da Secretaria Municipal de 
Educação Ciência e Tecnologia/Fundação Municipal de Educação (SEMECT/FME) 005/2015, que se fundamenta nesses documentos legais.

O Contexto da produção de texto relaciona-se com o contexto de influência, na medida em que se articula com a linguagem do interesse público e resulta das disputas pelos sentidos, em textos legais oficiais, pronunciamentos oficiais, textos políticos, ou comentários sobre os textos oficiais. No caso do SAEN, essa relação aparece na influência da política nacional, e, principalmente, ao identificar a quais sujeitos o texto é dirigido, nesse caso, à comunidade escolar, pois o SAEN "será implementado pela SEMECT/FME, por meio da Assessoria de Avaliação Institucional, em parceria com a comunidade escolar" (NITERÓI, 2015). Um exemplo da disputa de sentido aparece na portaria que regulamenta o SAEN quando se refere à "responsabilização participativa", deixando a cargo dos atores diretamente envolvidos nessa política a disputa pelo sentido de participação.

Com relação às políticas de avaliação externa e à implementação do SAEN na educação municipal, as entrevistas identificaram como os professores interpretam e reinterpretam essas políticas de avaliação. Isto é, identificou-se como o Contexto da produção de Texto, que pode ser escrito ou não, é interpretado no Contexto da Prática. Sobre essa abordagem, Mainardes (2006, p. 52-53) justifica que as "políticas são intervenções textuais, mas elas também carregam limitações materiais e possibilidades. As respostas a esses textos têm consequências reais. Essas consequências são vivenciadas dentro do terceiro contexto, o contexto da prática.”.

Mainardes (2006, p. 53) propõe que "esta abordagem, portanto, assume que os professores e demais profissionais exercem um papel ativo no processo de interpretação e reinterpretação das políticas educacionais e, dessa forma, o que eles pensam e no que acreditam têm implicações para o processo de implementação das políticas". É nessa esfera que a política sofre interpretações, podendo ser redefinida pelos sujeitos envolvidos.

Ouvir o que cada professor pensa, de acordo com suas experiências, sobre a incorporação das políticas públicas educacionais no que tange à avaliação externa na rede municipal de ensino de Niterói, a partir da criação do SAEN, assim como a análise documental que se refere a essa política, apresentou-se como um terreno fértil para entendermos como essas políticas de avaliação são recontextualizadas (BERNSTEIN, 1996) no Contexto da Prática nas diferentes realidades das escolas do segundo segmento do ensino fundamental.

A abordagem do Ciclo de Política possibilitou a análise de processos de forma não linear e não temporal e ainda proporcionou o distanciamento necessário entre o pesquisador e os entrevistados, na medida em que esse referencial "é uma ferramenta para investigação sobre as 
formas pelas quais políticas são feitas" (AVELAR, 2016, p. 8), pois a "política é feita pelos e para os professores; eles são atores e sujeitos, sujeitos e objetos da política" (BALL; MAGUIRE; BRAUN, 2016, p. 13).

A macropolítica de avaliação externa no Brasil é representada pelo SAEB, que se materializa nas escolas por meio da Prova Brasil. Essa macropolítica se concretiza no Contexto de Influência, se refletindo no campo da micropolítica, como, por exemplo, no caso da educação de Niterói, através do SAEN. Mainardes (2006, p. 52) argumenta que "o contexto de influência está frequentemente relacionado com interesses mais estreitos e ideologias dogmáticas, os textos políticos normalmente estão articulados com a linguagem do interesse público mais geral”.

Entretanto, o Contexto de Influência tende a ser reinterpretado no Contexto da Prática, no plano da micropolítica, no nosso caso, no universo dos professores do segundo segmento da rede municipal de educação de Niterói. Assim sendo, objetivamos analisar como os professores do segundo segmento do ensino fundamental percebem os impactos do SAEN no cotidiano escolar. De acordo com Sousa (2013), poucos são os estudos que analisam a implementação de avaliações em larga escala no âmbito municipal.

Em um universo de 51 (cinquenta e uma) unidades de educação de ensino fundamental, 12 (doze) atendem os anos finais do ensino fundamental. Essas escolas estão distribuídas em quatro das cinco regiões de planejamento do município, a saber: duas escolas na Região das Praias da Baía, sete escolas na Região Norte, duas escolas na Região de Pendotiba e uma escola na Região Oceânica. A Região Leste não possui escola que atende os anos finais do ensino fundamental.

Foram realizadas quatorze entrevistas, contemplando os professores que atuam em todas as áreas do conhecimento que compõem o currículo nos anos finais do ensino fundamental - um professor de Artes, dois de Ciências, um de Educação Física, dois de Geografia, um de História, um de Língua Estrangeira, quatro de Língua Portuguesa e dois de Matemática. Adotamos os seguintes critérios: contemplar todas as disciplinas do currículo; entrevistar professores com diferentes tempos de rede: foram sete com mais de 20 anos, que poderiam oferecer indícios da incorporação ou não das diversas políticas de avaliação; cinco professores entre 10 e 19 anos de rede, que vivenciaram boa parte da política de avaliação da SEMECT/FME; dois professores com menos de 10 anos, que não vivenciaram todo o processo relacionado à política pública de avaliação, mas apreendem de algum modo seus reflexos.

Procuramos também contemplar escolas de diversas regiões de planejamento do município de Niterói, pois possuem característica e realidades diferentes. Na Região Norte, onze professores 
foram entrevistados, em cinco escolas; na Região das Praias da Baía, um professor foi entrevistado, em uma escola das duas escolas dessa região; na Região de Pendotiba, foram entrevistados três professores, a Região Oceânica não foi contemplada nessa pesquisa, por ter somente uma escola municipal, que atende aos anos finais do ensino fundamental, bem como a Região Leste, por não possuir escola municipal desse segmento.

O SAEN foi criado pela Lei Municipal 3.067/2013, como um sistema de avaliação institucional, que a priori busca considerar outros elementos do contexto educativo, com o objetivo de alcançar uma qualidade da educação, sendo eles agrupados em quatro dimensões:

Art. 5'. A avaliação relativa à dimensão Gestão da Rede Municipal terá como finalidade avaliar as ações desenvolvidas pela SEMECT/FME, com o objetivo de qualificar a prática docente e propiciar a geração de condições adequadas de trabalho nas unidades escolares, por meio de um Programa de Monitoramento.

Art. 60. A avaliação relativa à dimensão Gestão Escolar terá como finalidade acompanhar e avaliar as ações realizadas pelos gestores das unidades escolares, com o objetivo de qualificar o trabalho administrativo e pedagógico, com vistas a sua organização e aperfeiçoamento.

Art. $\mathbf{7}^{\mathbf{0}}$. A avaliação relativa à dimensão Gestão do Trabalho Pedagógico terá como finalidade acompanhar e avaliar o desenvolvimento do trabalho docente realizado nas unidades educacionais da Rede Municipal de Educação de Niterói, com vistas a sua organização e aperfeiçoamento.

Art. $\mathbf{8}^{\mathbf{0}}$. A avaliação relativa à dimensão Gestão das Aprendizagens terá como finalidade promover um diagnóstico da aprendizagem dos alunos do Ensino Fundamental Regular e conhecer o contexto em que estão inseridos, bem como propor ações que possibilitem a qualificação do aprendizado (NITERÓI, 2015).

Treze dos quatorze entrevistados reduzem o SAEN ao Programa Avaliar para Conhecer, que é a avaliação externa da rede municipal, parte da Dimensão Gestão das Aprendizagens. O Programa Avaliar para Conhecer foi a primeira ação a ser implementada pelo sistema, ou seja, para o conjunto de professores, a estrutura e o funcionamento do sistema não são claros, a referência que eles têm do SAEN diz respeito à avaliação aplicada aos alunos nos anos de 2013 e 2015. Veja-se o depoimento a seguir

O SAEN é parecido com a Prova Brasil, a avaliação foi baseada nos descritores também. As provas do SAEN são feitas por professores da rede, mas também não atendem a realidade do aluno, que chega com muita dificuldade, eles não conseguem entender o que está sendo pedido, daí fazem de qualquer jeito. Eles sabem até o 
conteúdo, mas não estão familiarizados com o tipo de pergunta (Professora de Matemática há mais de 30 anos, grifos nossos).

Cinco dos quatorze entrevistados responderam que não sabiam quase nada ou muito pouco sobre o SAEN. "Eu só sei por conhecer os professores mais antigos que comentam. Porém, o conteúdo que é cobrado, a forma como essa prova é preparada (SAEN), eu desconheço completamente, nunca nem vi uma avaliação dessas." (Professor de Ciências há 2 anos)

No entanto, apesar das poucas informações que alegaram ter, três desses cinco professores teceram algumas críticas a esse tipo de avaliação.

Quase nada! Vocês inventaram isso aí, e já teve aqui. Nunca ninguém veio aqui ficar explicando. Sabe-se que professor que está em escola é meio reticente com relação à avaliação externa. Achamos que é perder tempo, pois está vindo de fora... sabe como é, quase nada! Pra mim não interfere em nada, não vimos resultado nenhum até hoje. Cadê o feedback? Não veio também. (Professor de Geografia há mais de 25 anos).

Como descrito no artigo 22 da Lei Municipal 3.067 que o institui, o SAEN é anunciado como um sistema de avaliação institucional, que

Será instituído pelo Poder Executivo Municipal um sistema de avaliação institucional da rede municipal de educação, formulado e implementado com o protagonismo das unidades de educação e de seus profissionais, com a finalidade de melhor conhecer e aprimorar a aprendizagem dos alunos, a gestão das unidades de educação, a gestão realizada pelos órgãos centrais da administração da educação municipal e o desenvolvimento do trabalho pedagógico nas unidades de educação (NITERÓI, 2013, grifos nossos).

Nota-se que o SAEN, em sua concepção, isto é, no Contexto da Produção de Texto, pretende articular outros setores da administração educacional que influenciam o contexto pedagógico e que podem contribuir com a aprendizagem dos alunos. Não se trata de avaliar o desempenho dos alunos de forma desarticulada de outros fatores que estão interligados a ele. Tratase, sim, de refletir como outros aspectos podem influenciar não só no desempenho, mas também a estrutura e o funcionamento da escola enquanto instituição social.

Entretanto, os aspectos de participação, protagonismo e a intenção de avaliar outras vertentes que influenciam o processo educacional, para além da aprendizagem dos alunos explicitados no Contexto da Produção de Texto presente no documento que concebe o sistema, não se configuram no Contexto da Prática, ou seja, no cotidiano escolar, os professores não percebem os desdobramentos e a abrangência do SAEN, porque no contexto da Prática a "política é 
reinterpretada pelos profissionais que atuam no nível micro" (MAINARDES, 2006, p. 60), nesse caso, a escola. Apesar da SEMECT/FME ter investido em programas voltados para melhoria da aprendizagem dos estudantes, a partir dos resultados apurados pelo SAEN, como o reforço escolar e a aceleração das aprendizagens, não são perceptíveis aos professores que tais ações sejam desdobramentos do Sistema de Avaliação.

Uma das 13 professoras lembrou que já houve outras iniciativas de avaliações externas em âmbito municipal e que o SAEN tem apenas o mérito de integrar a avaliação externa num sistema. Essa resposta reafirma, novamente, que para o conjunto dos treze professores entrevistados, o SAEN se restringe à avaliação externa da rede que foi aplicada aos alunos em 2013 e 2015. Outro depoimento que corrobora com essa opinião foi a comparação que uma professora fez entre o SAEN e as provas aplicadas pelo Sistema de Avaliação da Educação Básica do Rio de Janeiro (SAERJ) e em outros municípios:

É como o SAERJ, no estado, como as provas que o município do Rio também faz. Vários municípios implantaram esse sistema, que é para avaliar o índice de aprendizado dos alunos. E a partir daí, teoricamente, desenvolver propostas que possam melhorar a situação das escolas que não estejam adequadas (Professora de Português há 12 anos).

Apenas um dos entrevistados que mostrou ter mais informações sobre a estrutura do SAEN observou que o sistema avalia outros setores, para além da aprendizagem dos alunos, e lamentou que os resultados produzidos pela FME em relação às outras três dimensões do sistema não sejam divulgados para os professores e para as escolas.

Sei que é um sistema de avaliação de toda a rede, não só dos alunos, não só dentro das escolas, mas da própria FME. Infelizmente, os resultados dessa pesquisa interna não são divulgados para a propria rede. Eu sei que acontece, sei que os resultados são encontrados, mas a rede não conhece a avaliação que a própria FME faz do seu sistema de gestão. E isso eu acho muito ruim. O que é divulgado é apenas o resultado das escolas. Acho que esses resultados deveriam ser públicos. Como o sistema de gestão é avaliado? Como as coordenações são avaliadas? Eu gostaria muito de saber. Como se auto-avaliam e como as escolas avaliam esses setores da FME. (Professora de História há 17 anos, grifos nossos).

As outras dimensões avaliadas pelo SAEN geram relatórios internos, porém, as devolutivas para as escolas são realizadas individualmente, por meio das equipes pedagógicas que acompanham as unidades de educação. As devolutivas talvez não contemplem, no Contexto da Prática, os atores 
envolvidos no processo, como preconizado pelo documento que regulamenta o sistema, isto é, no Contexto da Produção de Texto:

Será implementado processualmente, no intuito de disseminar uma cultura avaliativa na Rede Municipal de Educação de Niterói, fundamentada em princípios democráticos e de responsabilização participativa, visando ao direito à informação, que proporcione o redimensionamento das ações, a fim de garantir a qualificação do processo de ensino e aprendizagem" (NITERÓI, 2015).

O SAEN, assim como o SAEB e outros sistemas de avaliações estaduais e municipais, é marcado pela avaliação externa aplicada aos alunos. Sobre isso, Bonamino (2013) explica que conceitualmente existem três gerações de avaliações: as avaliações de primeira geração são aquelas que têm como intenção apresentar uma diagnose, como é o caso do SAEB, cujos resultados são divulgados para consulta pública, mas não são devolvidos às escolas; nas avaliações de segunda geração, as escolas recebem os resultados, que também ficam disponíveis para consulta pública, entretanto há uma ampla divulgação desses resultados pela mídia através de rankings, como no caso da Prova Brasil, que associada ao fluxo escolar (taxa de aprovação), calculado a partir do Censo Escolar, compõe o Ideb, divulgado a cada dois anos. A terceira geração das avaliações externas tem como característica uma política de consequências fortes ou high stakes "e incluem, tipicamente, recompensas materiais em função dos resultados dos alunos e escolas. Nesse caso, contam-se experiências de responsabilização explícitas em normas que envolvem mecanismos de remuneração ou premiação em função de metas". (BONAMINO, 2013, p. 45).

Nessa perspectiva, o SAEN pode ser considerado um sistema cujas características se aproximam da segunda geração das avaliações externas, pois possui uma dinâmica que se assemelha especialmente no que se refere à avaliação externa - Programa Avaliar para Conhecer à Prova Brasil.

\section{CONSIDERAÇÕES FINAIS}

O estudo em questão teve como lócus o conjunto das doze escolas que integram o segundo segmento do ensino fundamental do município de Niterói. A pesquisa teve como objetivo analisar como os professores que atuam nesse segmento perceberam a implementação do SAEN - que comporta quatro dimensões: a Gestão da Rede Municipal, a Gestão Escolar, a Gestão do Trabalho Pedagógico e a Gestão das Aprendizagens, nesta última se insere a avaliação externa da rede - o 
Programa Avaliar para Conhecer - primeiro a ser implementado em 2013 (1 ${ }^{\text {a }}$ edição) e em 2015 (2. edição).

Para realizamos este estudo, utilizamos, além de entrevistas com os professores, a análise documental e a observação. A fim de articularmos essas informações, recorremos à abordagem do Ciclo de Políticas. Esse referencial permite reinscrever a análise da política nas influências mútuas entre os contextos macro e micro. Além disso, permite enfatizar os processos micropolíticos e a ação dos profissionais que lidam com as políticas no nível local, lançando luz sobre as possibilidades de intervenção e mudança postas pelas interações entre o contexto global e o contexto local.

O Ciclo de Políticas permitiu captar, por meio das entrevistas, que as políticas não são simplesmente implementadas, elas são interpretadas, pois "na prática, as escolas são constituídas de diferentes tipos, de diferentes gerações, de professores com diferentes disposições em relação ao ensino e à aprendizagem, fixados dentro de diferentes ondas de inovações e de mudanças". (BALL; MAGUIRE; BRAUN, p. 18, 2016).

Observamos que esse estudo dá indícios de que o caminho percorrido pela educação de Niterói, no tocante às políticas de currículo e avaliação, tem sido marcado pela inconstância na sua condução, tendo em vista os diferentes gestores que estiveram à frente da SEMECT/FME nos últimos vinte anos. Esses efeitos repercutem no universo da escola.

Por meio da observação e através dos depoimentos dos professores, constatamos que as experiências relativas às propostas de currículo e avaliação na rede não se consolidaram ao longo desse período, visto que a rede municipal em questão transitou entre três propostas de currículo e avaliação diferentes e, há cinco, seguindo uma tendência nacional, criou um sistema próprio de avaliação.

Após a criação do SAEN, foi iniciada uma nova discussão sobre a atual proposta pedagógica curricular intitulada: Referencial Curricular 2010. Ao final de 2015, uma comissão foi criada para formular um documento preliminar intitulado "Construindo a escola que queremos: repensando a organização pedagógica da rede municipal de educação de Niterói”, cujo debate pretendia ser ampliado entre as unidades escolares e seus atores. O documento traça concepções gerais de nova proposta pedagógica curricular, porém não aborda questões metodológicas referentes ao currículo e à avaliação. A discussão desse novo documento não se concretizou até o final dessa pesquisa.

Consideramos que tal iniciativa se fazia necessária, uma vez que ao criar um sistema de avaliação próprio, a educação municipal precisa articular o SAEN com os princípios norteadores 
presentes na sua proposta curricular, a fim de escapar de uma tendência apontada por Mainardes (2013, p. 186), de que "as mudanças no currículo, na pedagogia e na avaliação, configuradas a partir das políticas de avaliação e da definição de metas, têm levado ao fortalecimento do modelo pedagógico de desempenho". Ou seja, é necessário que o sistema não se proponha a atuar no âmbito dos resultados quantitativos e que dê um retorno de cunho pedagógico para as escolas. Esta política de avaliação tem provocado em muitas redes de ensino a redução do conceito de currículo com atenção voltada para a avaliação de desempenho dos alunos, seja interna ou externa. Assim criam sistemas próprios de avaliação, com objetivos de controle do desempenho dos alunos nos testes padronizados, deixando de aproveitar os resultados apresentados para obtenção de um diagnóstico qualitativo.

Acreditamos que as discussões acerca da avaliação devem suscitar uma constante reflexão sobre currículo, permitindo que as práticas docentes e discentes sejam revisitadas, possibilitando o encontro de novos caminhos metodológicos. Além disso, destacamos que o trabalho coletivo de elaboração do material avaliativo pode proporcionar crescimento teórico-prático a todos os participantes.

Assim sendo, torna-se necessário refletir sobre os objetivos e impactos dos processos avaliativos "que implicam necessariamente julgamento de valor e é preciso que se tenha consciência ética em relação aos objetivos, finalidades procedimentos empregados, socialização das informações e ações decorrentes e seus consequentes". (GATTI, 2013, p. 66).

Neste sentido, pensamos que cabe a um sistema de avaliação promover a articulação, a interação e a cooperação necessárias entre escolas e órgãos centrais, podendo essa relação ser estabelecida por meio da avaliação institucional, como preconiza o SAEN. Sobre isso, Freitas (2005, p. 930) argumenta: “a avaliação institucional, juntamente com um sistema de monitoramento de desempenho dos alunos, deve criar as condições necessárias para mobilizar a comunidade local das escolas na construção da sua qualidade e na melhoria de sua organização”.

A participação dos atores no Contexto da Prática é fundamental para que os efeitos de um sistema de avaliação como o SAEN sejam assimilados por todos os envolvidos, e que estes sintam a necessidade de interagir efetivamente com a avaliação institucional. Assim a manutenção e o aprimoramento de um sistema de avaliação não podem limitar seu tempo à duração de uma gestão governamental, rompendo com a lógica da descontinuidade das políticas públicas, durando, quase sempre, o período de uma única gestão. 
Essa premissa contribuiria, sobretudo, para que um sistema de avaliação como o SAEN fosse assimilado pela comunidade educativa, especialmente pelos professores, como os que deram voz a essa pesquisa, sendo capaz de contribuir para a melhoria da educação de forma ampliada e sistemática, como propõem as próprias diretrizes do SAEN, com implantação de todas as suas dimensões, de forma a não repercutir nos professores como mais uma prova vinda de fora, sem contribuições a oferecer às práticas pedagógicas e consequente melhoria da aprendizagem dos estudantes. Conforme o depoimento:

Eu não tenho muita informação, de como funciona. Às vezes recebemos da FME, alguns questionários, esse ano, nós não recebemos. A impressão que eu tive é que a FME não acatava as discussões das escolas, ou seja, vou deixar você falar, mas no final faremos o quisermos, para não dizer que não houve uma participação dos professores (Professora da rede há 14 nos).

Tal depoimento deixa claro que embora haja uma proposição do SAEN em articular outras dimensões, esse impacto não se expressa no Contexto da Prática.

Salientamos que a participação e o protagonismo, no que tange à implementação e gestão do SAEN, têm que ser exercidas de ambos os lados, tanto por parte dos gestores da SEMECT/FME, como por parte dos demais atores envolvidos, na busca da melhoria da educação municipal. Esse seria um dos pressupostos para que as avaliações externas contribuíssem para a qualidade local da educação, nas mais diversas realidades, fazendo, assim, sentido para os atores locais implicados no processo educacional.

Não podemos prever que caminhos o SAEN seguirá, uma vez que é um sistema cuja instituição se deu recentemente e ainda se encontra em fase de implementação. Acreditamos que o futuro do SAEN dependerá dos próximos gestores e do entendimento que estes tenham de um sistema de avaliação institucional, pois uma política pública sofre influências externas de cunho nacional, mas é conduzida, na esfera local, por aqueles que gestam essa política em um determinado período de tempo/espaço. 


\section{REFERÊNCIAS}

ALVES-MAZZOTTI, Alda J.; GEWANDSZNAJDER, Fernando. O planejamento de pesquisas qualitativas. O método nas ciências naturais e sociais: pesquisa quantitativa e qualitativa. São Paulo: Pioneira, 1998.

AROSA, Armando C. O Ensino Fundamental na Rede Municipal de Niterói: ciclo e resseriação. In: Educação em foco, Juiz de Fora, v 17 n. 3, p. 133-151, nov. 2012 / fev. 2013. Disponível em: http://www.ufjf.br/revistaedufoco/files/2013/ 10/cap-06-4.pdf. Acesso em: 10 de março de 2016.

AVELAR, Marina. Entrevista com Stephen J. Ball: uma Análise de sua contribuição para a Pesquisa em Política Educacional. Revista académica evaluada por pares, independiente, de acceso abierto y multilíngüe. Vol. 24, n. 24, p. 1-18, fev. 2016. Disponível em: https://www.researchgate.net/publication/296631339_Entrevista_com_Stephen_ J_Ball_Uma_Analise_de_sua_Contribuicao_para_a_Pesquisa_em_Politica_Educacional. Acesso em: 03 de junho de 2017.

BALL, Stephen; MAGUIRE, Mag; BRAUN Annete. Como as escolas fazem políticas: atuação em escolas secundárias. Minas Gerais, UEPG, 2016.

BAUER, et al. Avaliação em larga escala em municípios brasileiros: o que dizem os números? Estudos em Avaliação Educacional, São Paulo, v. 26, n. 62, p. 326-352, maio/ago, 2015. Disponível em: http://publicacoes.fcc.org.br/ ojs/ index.php/eae/article/view/3207. Acesso em 08 de fevereiro de 2017.

BONAMINO, Alicia. Avaliação Educacional no Brasil 25 anos depois: onde estamos? In: BAUER, Adriana; GATTI, Bernadete A. (Org.). Ciclo de Debates: vinte cinco anos de avaliação de sistemas educacionais no Brasil - implicações nas redes de ensino, no currículo e na formação de professores. Florianópolis: Insular, 2013. p. 43-60.

BOWE, R.; BALL, S.; GOLD, A. Reforming education \& changing schools: case studies in policy sociology. London: Routledge, 1992.

GATTI, Bernadete. Possibilidades e fundamentos de Avaliações em larga escala: primórdios e perspectivas contemporâneas. In: BAUER, Adriana; GATTI, Bernadete A.; TAVARES, Marialva R. (Org). Ciclo de Debates: vinte cinco anos de avaliação de sistemas educacionais no Brasil, origens e pressupostos. Florianópolis: Insular, 2013. p. $47-$ 69.

BERNSTEIN, Basil. A estruturação do discurso pedagógico: classes, código e controle. Petrópolis, RJ: Vozes, 1996.

BRASIL. Lei 9.394/96, de 20 de dezembro de 1996. Disponível em: http://www.planalto.gov.br/CCIVIL_03/ leis/ L9394. htm. Acesso em 03 de setembro de 2015.

Resolução CNE/CBE n 4/2010. 2010. Disponível em: http://portal.mec.gov.br/dmdocuments/rceb004_10. pdf. Acesso em: 09 de fevereiro de 2015.

Lei no 13.005, de 25 de junho de 2014. Disponível em http://www.planalto.gov.br/ccivil_03/_ato20112014/2014/lei/113005.htm. Acesso em: 02 de fevereiro de 2015.

CASTRO, Helena Guimarães de. Sistemas de avaliação da educação no Brasil: avanços e novos desafios. Perspectiva, São Paulo, v. 23, n. 1, p. 5-18, jan./jun. 2009. Disponível em: http://produtos.seade.gov.br/produtos/spp/v23n01/v23n01 _01. pdf. Acesso em: 28 de agosto de 2015.

CUNHA, Viviane Gualter Peixoto. Trajetória da política de ciclos na rede municipal de educação de Niterói-RJ (19992012): análise do processo de recontextualização do discurso pedagógico nos textos oficiais. 2013 . 236 f. Tese (Doutorado em Educação) - Pontifícia Universidade Católica do Rio de Janeiro, Rio de Janeiro, 2013.

ESTEBAN, Maria T.; AFONSO, Almerindo J. Avaliação: reconfigurações e sentidos na construção de um campo. Olhares e Interfaces: reflexões críticas sobre a avaliação. São Paulo: Cortez, 2010.

FERNANDES, Claudia de Oliveira. A Escolaridade em Ciclos: práticas que conformam a escola dentro de uma nova lógica - a transição para a escola do século XXI. 2003. 354 f. Tese (Doutorado em Educação) - Pontifícia Universidade Católica do Rio de Janeiro, Rio de Janeiro, 2003.

FERNANDES, Reynaldo. Índice de Desenvolvimento da Educação Básica (Ideb). Brasília: Instituto Nacional de Estudos e Pesquisas Educacionais Anísio Teixeira, 2007. Disponível em: http://portal.inep.gov.br/documents/ 186968/485287/\%C3\%8Dndice+de+Desenvolvimento+da+Educa\%C3\%A7\%C3\%A3o+B\%C3\%A1sica+\%28Ideb\%29 /26bf6631-44bf-46b0-9518-4dc3c310888b?version=1.4. Acesso em: 10 de maio de 2015. 
. A universalização da avaliação e a criação do Ideb: pressupostos e perspectivas. Sistema de Avaliação da Educação Básica (SAEB): 25 anos. Em Aberto. Brasília, v. 29, n. 96, p. 1-230, maio/ago. 2016. Disponível em: http://emaberto.inep.gov.br/index.php/emaberto/article/view/2603/2613. Acesso em: 28 de outubro de 2017.

FREITAS, Luiz Carlos de. Qualidade negociada: avaliação e contraregulação na escola pública. Educação \& Sociedade. Campinas, vol. 26, n. 92, p. 911-933, Especial - Out. 2005. Disponível em http://www.cedes.unicamp.br. Acesso em: 10 de agosto de 2017.

FREITAS, Dirce Ney Teixeira de. D. Avaliação da Educação básica no Brasil: características e pressupostos. In: BAUER, Adriana; GATTI, Bernadete A.; TAVARES, Marialva R. (Org). Ciclo de Debates: vinte cinco anos de avaliação de sistemas educacionais no Brasil, origens e pressupostos. Florianópolis: Insular, 2013. p. 70-96.

MAINARDES, Jefferson. Abordagem do ciclo de políticas: uma contribuição para a análise de políticas educacionais. Educação \& Sociedade. Campinas, vol. 27, n. 94, p. 47-69, jan./abr., 2006. Disponível em <http://www.cedes. unicamp.br. Acesso em 10 de fevereiro de 2016.

. As relações entre currículo, pedagogia e avaliação no contexto das avaliações de sistemas educacionais. In: BAUER, Adriana; GATTI, Bernadete A. (Org.). Ciclo de Debates: vinte cinco anos de avaliação de sistemas educacionais no Brasil - implicações nas redes de ensino, no currículo e na formação de professores. Florianópolis: insular, 2013. p. 179-192.

MACHADO, Cristiane; ALAVARSE, Ocimar Munhoz; ARCAS, Paulo Henrique. Sistemas estaduais de avaliação: interfaces com qualidade e gestão da educação. Revista Brasileira de Política e Administração da Educação, vol. 31, n. 3, p. 667 - 680 set./dez. 2015. Disponível em: http://seer.ufrgs.br/index.php/rbpae/article/view/63800/37029. Acesso em: 10 de janeiro de 2017.

MATHEUS, Danielle dos Santos. Políticas de Currículo em Niterói, Rio de Janeiro:o contexto da prática. 2009.166 f. Dissertação (Mestrado em Educação) - Universidade do Estado do Rio de Janeiro, Rio de Janeiro, 2009.

NITERÓI. FUNDAÇÃO MUNICIPAL DA EDUCAÇÃO DE NITERÓI. Lei 3.067, de 12 de dezembro de 2013. Acesso em: 09 de janeiro de 2017. Disponível em: https://leismunicipais.com.br/a/rj/n/niteroi/lei-ordinaria/2013/ 307/3067/lei-ordinaria-n-3067-2013-institui-o-novo-plano-unificado-de-cargos-carreira-e-vencimentos-dos-servidoresda-fundacao-municipal-de-educacao-de-niteroi?q=lei\%203067\%2F2013. Acesso em: 10 de junho de 2015.

SEMECT/FME. Portaria SEMECT/FME n⿳ 005/2015. Dispõe sobre a regulamentação do Sistema de Avaliação da Educação de Niterói (SAEN). 2015.

PESTANA, Maria Inês. O sistema de avaliação brasileiro. Revista brasileira de Estudos Pedagógicos. Brasília, v.79, n.191, p.65-73, jan./abr. 1998. Disponível em: http://rbep.inep.gov.br/index.php/rbep/article/view/1044/1018. Acesso em: 05 de maio de 2015.

SILVA, Maria Abádia da. Qualidade social da educação pública: algumas aproximações. In: Cadernos. Cedes, Campinas, vol. 29, n. 78, p. 216-226, maio/ago. 2009. Disponível em http://www.cedes.unicamp.br. Acesso em: 05 de maio de 2015.

SOUSA. Sandra Zákia. Avaliação Externa em Larga Escala no âmbito do estado brasileiro: interfaces de experiências estaduais e municipais de avaliação da educação básica com iniciativas do governo federal. In: BAUER, Adriana; GATTI, Bernadete A. (Org.). Ciclo de Debates: vinte cinco anos de avaliação de sistemas educacionais no Brasil implicações nas redes de ensino, no currículo e na formação de professores. Florianópolis: insular, 2013. p. 61-86. 


\section{RESUMO}

Este estudo, inserido no contexto do Sistema de Avaliação da Educação Básica (SAEB), objetivou analisar a percepção dos professores dos anos finais do ensino fundamental sobre as políticas públicas de avaliação educacional, após a implantação na rede municipal de ensino do Sistema de Avaliação da Educação de Niterói (SAEN) em 2013. Foi utilizada como aporte teórico-metodológico a abordagem do Ciclo de Políticas, sugerido por Ball e colaboradores. Esse referencial embasou a análise documental, das entrevistas, bem como os achados da observação. A pesquisa indicou que existem diferentes interpretações dos professores sobre os impactos do SAEN, assim faz-se necessário que os sentidos de participação e protagonismo presentes na concepção do SAEN se tornem realidade no Contexto da Prática.

Palavras-chave: Sistema de Avaliação da Educação de Niterói (SAEN); Percepção dos Professores; Ciclo de Políticas.

\section{EDUCATION EVALUATION SYSTEM OF NITEROI: PERCEPTION OF TEACHERS IN THE PRACTICECONTEXT}

\section{ABSTRACT}

This study, related to the context of the Basic Education Evaluation System (SAEB), aimed to analyze the Fundamental School final years teachers' perceptions about public policy on educational evaluation, after the Education Evaluation System was implemented in Niteroi schools (SAEN) in 2013. It was used as theoreticalmethodological approach the Politics Cycle, suggested by Ball and collaborators. This approach supported the document analysis, interviews, as well as the findings of the observation. The research has indicated that there are teachers' different interpretations about the impacts of SAEN, so it is necessary that the meanings of participation and protagonism present in the design of the SAEN become true in the context of the practice.

Keywords: Niteroi Education Evaluation System (SAEN); Teachers perceptions; Politics Cycle.

\section{SISTEMA DE EVALUACIÓN DE LA EDUCACIÓN EN NITEROI: PERCEPCIÓN DE LOS DOCENTES EN EL CONTEXTO DE PRÁCTICA}

\section{RESUMEN}

Este estudio, inserta en el contexto de la evaluación del sistema de educación básica (SAEB), analiza las percepciones de los maestros de los últimos años de enseñanza fundamental acerca de las políticas públicas de evaluación educativa, después de la implantación del sistema de evaluación de la educación de Niterói (SAEN) en 2013. Fue utilizado el enfoque teórico-metodológico Ciclo de Políticas, propuesto por Ball y colaboradores. Esto referencial embasó el análisis de documentos, entrevistas y los resultados de la observación. La investigación ha indicado que hay diversas interpretaciones de los maestros acerca de los impactos de SAEN, así es necesario que los significados de participación y protagonismo del SAEN se convertan en el contexto de la práctica.

Palabras clave: Sistema de evaluación de la educación de Niterói (SAEN); Percepción de los docentes; Ciclo de Políticas. 